\title{
Evaluating the National Literacy Acceleration Programme on the Teaching of Language and Literacy in Lower Primary Schools of Upper West Region of Ghana
}

\author{
Blaise Dery Man ${ }^{{ }^{*}} \quad$ Titus Nuobepuor $^{2} \quad$ Eugene Naah Kogri ${ }^{3} \quad$ David Angbataayele Kpogwiiri ${ }^{4}$ \\ 1.Tumu College of Education, Box 19, Tumu-Upper West Region, Ghana \\ 2.Tumu College of Education Demonstration Basic School, Box 19, Tumu-UW/R \\ 3.St John Bosco's College of Education, P. O. Box 11, Navrongo, Upper East Region \\ 4.Tumu College of Education, P. O. Box 19, Tumu-Upper West Region, Ghana
}

\begin{abstract}
This study sought to evaluate the National Literacy Acceleration Programme (NALAP) on the teaching of language and literacy from the Kindergarten to primary three (KG1-P3). The scope of the study covered only lower primary teachers. The design was cross-sectional research design. Three instruments; namely, questionnaire, interview guide, and document analysis were used for the data collection. The population for the study comprised 1852 lower primary teachers of the Upper West Region with an accessible population of 656 and sample size of 100 teachers. Multiple sampling techniques such as quota sampling technique, purposive and simple random sampling techniques were used. Quota sampling technique was used to select 20 teachers from each district. Purposive sampling technique was also used to select five districts lower primary teachers among eleven the districts. Two teachers were also purposively selected from among the overall sample from each district for the interview. Simple randomly sampling technique was used to select four schools in each district with five teachers from each school. Two schools in each district were involved in the document analysis. The results were analyzed using frequency tables and percentages. The findings revealed that NALAP was implemented to some extent and its methods and strategies including the materials were being used to some extent. Results again showed NALAP teaching and learning materials were available in the schools but were insufficient and some schools had none at all. Recommendations were made for the provision of teaching learning materials, training of teachers in bilingual bi-literacy methods of teaching to enable them teach language and literacy proficiently and in-service programmes for serving teachers in the system. And finally, suggestions were made for further studies.
\end{abstract}

Keywords: Assessment, bi-literacy, communication, implementation, Language, medium and policies

DOI: $10.7176 /$ JLLL/55-07

Publication date: April $30^{\text {th }} 2019$

\subsection{Introduction}

Language is one of human beings' major means of expression. It plays a major role in the education of the child both formally and informally. It is the key to communication and understanding in the classroom. The use of Language in everyday communication is therefore very important and it is through language that literacy can be developed. Without language there will be no literacy development because it is through the use of language that the four major language skills are developed. Therefore, the study of language is very important and literacy proficiency in both first language (L1) and second language (L2) in particular and in other academic disciplines in general is also very necessary for lower primary school pupils. However, this aspect has been very low in our basic schools and as a result various language policies have been implemented mostly without success though.

The development of effective Language and Literacy is therefore crucial to the child's life and his/her entire learning. A child's journey to building strong language and literacy skills starts from infancy and continues throughout the early childhood years and beyond. According to the Ghana Education Service [GES] (2014, p.2) all aspects of literacy play an integral part of the child's education. Reading in particular, underpins all subjects, as it enables children to access all areas of the curriculum. Consequently, this makes cross-curricular links possible. For instance, demonstrating the ability to read and understand a mathematical word problem in order to solve it is a sign of literacy ability and skills. It is therefore very important that teachers and all other educators teach, encourage and facilitate literacy learning in the lower classes.

Attaining an appreciable level of literacy is a process and not an event. It can actually take a life time to achieve (Elkin, 2007). Literacy is a skill that is a very essential pillar of every child's development, if the child will succeed in his/her education and contribute to the growing population of literate society. In fact, literacy forms the fundamental building blocks of every child's academic life. The rate at which pupils acquire these requisite skills is clearly known to be a strong indicator of the future success in pupils' academic performance and implication for society as a whole (Chen, 2005).

In a multi-lingual society like Ghana, there cannot be proper development without adequate development of 
people's languages and literacy. Language is explained as a structured system of arbitrary vocal conventional symbols by means of which members of a social group interact (Bram, 1967) cited in Owu-Ewie (2006). It is the ability to acquire and use complex systems of communication, particularly the human ability to do so. It is the expression of ideas by means of speech-sounds combined into words. Cook (2000) contends that language is the centre of human life. We use it to express our love or our hatred, to achieve our goals and further our career, to gain artistic satisfaction or simple pleasure. Language is the pivot on which all human life activities revolve.

Literacy, on the other hand, is referred to as a set of observable skills especially ones relating to one's intellectual ability to read and write (UNESCO, 2006). According to the Ghana Education Service (2014, p.2), "literacy is the ability to read, write, view, design, speak, listen, identify, understand, interpret, create, compute, use print and written materials associated with varying contexts. It is also the ability to communicate effectively and to make sense of the world." Literacy involves a continuum of learning that enables an individual achieve his/her goals, to develop his/her knowledge and potential to participate fully in the wider society. Literacy is also the ability to read and write at an adequate level of proficiency that is necessary for communication.

Thus, the importance of language and literacy in our schools' instruction is very crucial in lower primary school pupils' literacy development. However, the issue of the best language of instruction in schools has been a thorny one for years in many African countries, including Ghana. Language-in-education policy in Ghana, has been changing over the years and particularly so after independence.

Since independence, successive governments in Ghana have implemented various language policies with much concern for the English Language because it is the official language used in all our transactions. This means that the government's policy on language of instruction has changed many times over several decades. For instance, from 2002 to 2009, the government mandated English-only instruction which generated intense public interest and was met with a lot of criticisms from sections of academicians, politicians, educators, traditional rulers and the general populace. This policy did not last long and the situation reversed to the one that was in practice before (Owu-Ewie, 2013). According to Seidu, Mereku, Avoke, Ekumah, Tamanja and AdzahlieMensah (2008) cited in Tamanja (2010) community reactions paid off when the president at that time set up a committee to review the entire education system. The committee recommended that either the local or the English language should be used as medium of instruction at the kindergarten and lower primary as appropriate (Ministry of Education Science and Sports [MOES], 2003). Following the recommendation, the government's white paper 2004 announced that;

Government accepts the recommendation that the children's first home language and Ghana's official language, English, should be used as the medium of instruction at the kindergarten and primary level (AnamuaMensah, 2004)

With this recommendation, the English only policy which was in place before, did not last long and a change again was introduced with the inception of National Literacy Acceleration Programme (NALAP) through a partnership between the Ghana Education Service (GES) and the United States Agency for International Development (USAID) as part of the Education Quality for All (EQUALL) project in 2008 (GES, 2014). The language policy with the inception of NALAP was that the medium of instruction in kindergarten (KG) and lower primary should be a Ghanaian language and English where necessary. English, the official language of the country is introduced gradually from KG and becomes the medium of instruction from Primary 4 onwards (Ministry of Education, Science and Sports, 2008).

The overall goals of the NALAP programme were; first to equip the majority of children leaving the basic education system with skills of literacy that would improve their learning abilities and serve as a springboard for further academic pursuit. Second, it also meant that by primary 3, pupils would be functionally literate and numerate and would achieve reading fluency in both the mother tongue (L1) and the English language (L2) (MOESS, 2008). The objective of NALAP is to provide instruction in the predominant Ghanaian language of the local community of the pupils through KG1 to P3 with English being introduced in primary 4. The assumption of the programme is that the pupils would first become fluent speakers and readers of the local language of instruction and immediately followed with the English language skills.

One prominent issue about NALAP is that, it is a bilingual literacy programme in which pupils learn to read in a Ghanaian language. The pupils also learn to speak English at the same time, but they do not read English until primary 2. NALAP approach is based on studies that show that pupils learn to read and write better and faster in a language they know well, and the skills acquired in the local language is transferred to reading a second language.

In order to ensure the success of the programme, EQUALL project with the assistance of USAID developed a lot of teaching and learning materials for the early grade pupils in 11 officially approved and recognized Ghanaian languages for instruction. These languages were Akwapem Twi, Asante Twi, Dagaare, Dagbani, Dangme, Ewe, Fante, Ga, Gonja, Kasem and Nzema (GES, 2014). Contrary to the approved languages, additional languages such as Gurune, Kusal, Buli and Likpakpa are also being developed, and some studied in the Universities just like the others taught in the lower primary without officially being taught in basic schools. 
With the materials developed in all the eleven Ghanaian languages approved for study in schools, their introduction became one of the most far-reaching reforms of education system in Ghana (MOESS, 2008). The materials were prepared in conformity to the syllabus with standards which milestones and reflect the cultural values and practices of the pupils. The standards state what the pupils should know and be able to do while the milestones state the steps along the way to reaching the standards. These standards cover the four major language skills.

The central purpose of NALAP is to contribute to an increase in the literacy rate for early grade primary school pupils. Reports from national assessments show that the great majority of primary pupils cannot read with understanding in their first language or in English. In June 2009 a Baseline Assessment for NALAP implementation found that only $18 \%$ of third grade pupils could read text in their school's Ghanaian language (Leherr, 2009), and at grade six the National Education Assessment (NEA) of 2007 also found that 15\% of P3 and $26 \%$ of P.6 pupils had minimum competency in English (MOESS, 2007). In 2011 the proficiency level in English for P3 and P6 learners was 42.9\% and 48.6\% respectively (NEA, 2012). The criterion Reference Test of 2000 also indicated that fewer than $10 \%$ of primary school children at level six are able to read with the ability of the grade level (Moomen, 2006).

Though there has been slight improvement in literacy rate since 2008 to date, the result is still unsatisfactory vis-à-vis the standards set by the Ministry of Education. As indicated in the National Education Assessment (NEA) report, test information in Ghana has consistently indicated problems in the learning repertoires for pupils and these problems have persisted. While the education system is improving, test scores have only marginally improved over the years. This gives credence that the fundamental problem facing Ghanaian children is that of basic literacy skills. It is clear that the phenomenon of these very low rates of literacy and learning has been relatively neglected during the past, with our rapid expansion of primary schooling to meet our constitutional mandate, and the international Education for All target of having all school-age children enrolled in basic education. The consequence is that most children experience and leave school crippled by their inability to access and use text as a tool of understanding. As a result, schooling becomes more a matter of memorization than comprehension. This is a major constraint to Ghana's socio-economic development that a large proportion of our children and youth are unable to comprehend and to learn from text, or to write with fluency (Hanushek and Wossman, 2007).

As a follow up to ensure that NALAP is well implemented after the development of the materials and Baseline assessment, the project organized workshops for National Resource Team members who in turn trained 5 circuit supervisors of all the districts in the country for further training of KG1 to P3 teachers. In addition to this, all the circuit supervisors, headteachers, and language tutors of Colleges of Education were also trained to ensure NALAP is adequately well implemented. The hope is that NALAP will provide a realistic solution to the problem of local language literacy development in Ghana and this could present a model programme for other African countries battling with language policy problems to emulate.

Despite all these language policy issues, English which is still used in the education system is a second language for all Ghanaians and as such, some Ghanaians cannot speak it. A vast majority of Ghanaian children learn to speak, read and write English for the first time in school. As a result of difficulties in language policy issues, some Ghanaians feel the mother tongue policies that were implemented do not always favour the study of the English language too in schools. It is in this light that Daaku (2010) explained that the misconception that the use of local dialect as a medium of instruction in pre-school does not promote proficiency in English language and academic achievement was hindering the efforts of the National Literacy Accelerated programme.

Looking at the Ghanaian situation, approximately, we have about sixty (60) languages spoken in the country and none of these is a national language (Dowuona-Hammond \& Asante-Frempong, 2000). As such, the issue of language policy in Ghana as a multi-lingual country, and for that matter language of instruction in the lower primary schools has always been the subject of public and academic debate and full of controversy. As indicated earlier, some object to the use of the mother tongue as the medium of instruction, especially in the lower primary schools, on the basis that the child knows his/her mother tongue before he/she comes to school. Therefore, there is no need for the school to teach him/her again.

To support the use of mother tongue with empirical evidence, various researches on language in education have established facts that the use of the L1 as medium of instruction during one's early years of schooling, results in improved acquisition of knowledge by pupils (Andoh-Kumi, 1992; Fafunwa, Macauley \& Funnso, 1989). It has also been established that the use of the mother tongue as language of instruction is effective in helping with the acquisition of second languages. As indicated earlier, it is quite clear the study of language is very important and Literacy proficiency in both first language (L1) and second Language (L2) in particular and in other academic disciplines in general is also very necessary. In the same way, the importance of language and literacy in our schools' instruction is very crucial for lower primary school pupil's literacy development. Unfortunately, this aspect has been very low in our schools and this is as a result of the various language policies implemented over the years without success due to so many reasons. 
Significant amongst language policies issues is the belief of some people that the policy itself largely accounts for the low level of literacy in English among pupils and students. Lack of resources, teacher preparedness, and other concerns confound schools' ability to carry out the policy as intended. Negative attitudes toward the use of Ghanaian languages in instruction also compound the problem (Improving Education Quality [IEQ], June 28, 2000). Language use in school is very necessary and has two basic academic functions. In the first place, teachers use language to teach new content and concepts while pupils are expected to learn them through language. Secondly, teachers use language to teach language and to help pupils learn it. With all these importance, the issue of the best language of instruction in schools continues to be a thorny one for years not only in Ghana but also in many African countries. Language-in-education policy in a multilingual society like Ghana has been a controversial issue since British colonial rule, but particularly so after independence. As Ouadraogo (2000, p.89) stated "Education and language issues are very complex in Africa because of the multiethnic, multi-lingual situation". The situation is even more severe when the official language of the nation is different from any of the indigenous languages. There is always a controversy over which language to use in school especially at the lower primary level in multilingual societies.

Sixty years after independence, Ghana is still grappling with which particular language to use as the medium of instruction in the lower primary school (now KG1 to primary 3). Therefore, English the language of our colonial masters continues to play a prominent role and is officially used in our formal educational system. This implies that all Ghanaians who attend school must study English and majority of them cannot speak it. Just the same, our children learn to speak, read and write English for the first time in school. This therefore, is a challenge for basic school pupils in the country because most of them speak different indigenous Ghanaian languages (Dowuona-Hammond \& Asante-Frempong, 2000).

Currently, in the Upper West region, we have about three distinct languages spoken and they include Dagaare, (Birifo, Chakala, Dagara Manlaala, waale inclusive) Sissali and Kasem. However, Baker (1986) as cited in Duut (2019) indicated authorities listed below that Upper West Region is ethno linguistically diverse with at least eight languages spoken in the region surveyed (Cardinall, 1925; Rattray, 1932 \& Kropp-Dakubu, 1989). There are therefore, schools particularly concentrated in both Sissala East and West of Upper West Region, where pupils and teachers do not know or speak one of the 11 officially approved languages. If NALAP is to succeed in these areas, teachers need help in making use of the L1 materials or working with the GES to devise other methods of teaching L1 literacy and oral English in the early grades.

\subsection{Statement of the Problem}

From the introduction, there is evidence that NALAP is implemented in certain basic schools in Ghana (Dowuono-Hammond \& Asante-Frempong, (2000). However, in the basic schools in the Upper West Region it seems the implementation is not properly done because most pupils in the lower primary still find it difficult to read and write in L1 and L2 (EGRA, 2014). There is limited literature to establish the fact for the proper implementation of the NALAP and Language and Literacy policy programmes in the region. NALAP is an ongoing process and as such there is the need to evaluate it. According to Print (1993, p.188), 'Process evaluation examines the experiences and activities involved in the learning situation; that is making judgements about the process by which students acquire learning or examining the learning experience before it is being concluded'.

In the context of this study, the assumption is that various language policies in Ghana have failed to achieve the desired objectives (Owu-Ewie, 2013). A serious issue of concern is that most of the lower primary pupils in the Basic schools in the Upper West Region can neither read nor write the mother tongue or the second language effectively. According to the 2014 Early Grade Reading Assessment, most pupils in Ghana are performing poorly in reading and numeracy. The report states that "in general only the top $2 \%$ or fewer were able to read with fluency and comprehension" (MOE, 2015, P1). The ability to read and write in our basic schools is therefore a serious problem in most of the schools in Upper West region.

It is also a widely acknowledged fact that, despite decades of literacy campaigns especially in the north and recent campaigns by 'The Break Through to Literacy' (BTL) / Bridge to English (BTE), (Moomem, (2006) NALAP, NGOs, Complementary Basic Education (CBE) and others, much has not been achieved. Another problem worth noting is that after the implementation of policies and programmes, there is often lack of followup to evaluate them to find out whether they are progressing or not. It therefore, appears the language policy being practised in the basic schools leaves much to be desired. It is in the light of all these policy problems that the Ghana Education Service with support from the government in conjunction with the USAID conducted Early Grade Reading Assessment (EGRA) all over the country in 2013 to assess the reading skills in 11 Ghanaian languages and English. The Early Grade Reading Assessment showed that by the end of primary 2, majority of public school pupils could not yet read with comprehension, neither in a Ghanaian language nor in English. In the 11 languages assessed, at least half, and often more, of the pupils assessed could not read a single word correctly. 
It therefore, seems the NALAP and the Language and Literacy policy as practised in the lower primary schools have not lived up to expectation. The questions to ask are; to what extent is the involvement of teachers in the NALAP implementation? Do teachers use adequate methods in the teaching of language and literacy? Do the basic schools have adequate resources for the teaching and learning of language and literacy? Answers to these questions and many others are not known. It is against this background that the study sought to evaluate the National Literacy Acceleration Programme on the effective teaching and learning of language and literacy in selected lower primary schools in the Upper West Region of Ghana. The objectives of the study were therefore to examine whether teachers have implemented and are using the NALAP methods, strategies and materials in the teaching of language and literacy in the lower primary schools. The study was therefore, guided by the following research questions:

Research question one: How effective is the involvement of teachers in the implementation of the NALAP in the teaching of Language and Literacy?

Research question two: How efficiently have the teachers been using the teaching methodologies and strategies of NALAP in the teaching of language and literacy in the lower primary schools?

Research questions three: To what extent has the use of NALAP materials been implemented in the lower primary schools?

\section{1 .1 Significance of the Study}

The findings of this study will benefit the classroom teacher and inform him/her to adopt suitable methods in the teaching and learning of Language Literacy at the lower primary level. This will improve their teaching methods and strategies in handling language and literacy lessons at the lower levels so that a solid foundation is laid for the pupils to build on as they progress to the upper classes. It will also help teachers improve upon their skills in bilingual-biliteracy teaching in the lower primary schools for the overall improvement of biliteracy skills among lower primary pupils. It is also envisaged that findings of the study will contribute to existing literature on language development policies. The findings that emerge from this study will also generate the interest of other research institutions and Universities to carry out further research into other areas of language and literacy and language policy issues. Thus, other researchers as well may also use this study material as a source of reference in their studies. And finally, the study will again benefit educational policy makers, the Teacher Education Unit, the National Teaching Council, the Ghana Education Service, all other stakeholders in education, and trickle down to the basic school teachers and pupils in basic schools.

\subsubsection{Delimitation and Scope of the Study}

The study was focused on only lower primary teachers of basic schools; that is, from KG 1-P3 in the Upper West Region of Ghana. The languages of instruction in our lower primary schools are the local language (L1) and English language (L2). The scope of the study therefore, was limited to National Literacy Acceleration Programme to the study of language and literacy in the lower primary schools. Therefore, upper primary school teachers and Junior High School teachers were not included in the study. There are also about two hundred and sixteen (216) Districts in the whole country. However, this study focused on only five districts in one region. This might have affected generalization of the findings. The study could have covered all lower primary schools in the region but only a few in the five districts were covered.

Again, uncompromising attitude of some teachers made it difficult to carry out the study as scheduled. Other teachers thought the researcher was doing this study to uncover their weaknesses and report to Ghana Education Service. Thus, some were reluctant to respond to the questionnaire with the reasons that it was overloaded and they were preparing their pupils for end of third term examination.

\subsection{Methodology}

The study used a Cross-sectional research design. The cross-sectional design was used because it is flexible in using different instruments for the data collection (OUT 2010). This cross sectional design employed mixed method to get in-depth views of about the implementation of NALAP in lower primary schools. Descriptive statistics was used for the data analysis. This design was used to gather qualitative and quantitative data for the analysis and to determine the extent to which NALAP methods, strategies and materials are used in the teaching of language and literacy. The population for the study comprised 1852 lower primary school teachers (KG1 - P3) of Upper West Region of Ghana. The reason for using the lower primary teachers is that they teach language and literacy in the schools and would be able to provide accurate information. The sample for the study comprised one hundred (100) lower primary school teachers made up of $75 \%$ females and $25 \%$ males. Multiple sampling techniques such as purposive, simple random and quota sampling techniques were used. Ten (10) teachers were chosen from the sample for the interview and 20 schools for the document analysis. The instruments used for data collection for the study were questionnaire, document analysis, and interview. The questionnaire involved structured questionnaire. A four-point response questionnaire was designed using Likert scale of strongly agree, agree, disagree and strongly disagree with values 4, 3, 2, 1 respectively. In analyzing the data 'strongly agree and agree' were merged for 'agree' and 'disagree and strongly disagree' also merged for 'disagree'. Qualitative data 
collection approach was employed because qualitative data could best be obtained through the use of questionnaire, interviews, and document analysis. The data were analysed using the Statistics Product for Service Solution (SPSS) version 20 software in frequencies and percentages.

\subsection{Results and Discussion}

Research Question 1

How effective is the involvement of teachers in the implementation of the NALAP in the teaching of Language and Literacy?

This question sought to find out how effectively teachers are involved in the implementation of the National Literacy Acceleration Programme in the teaching and learning of Language and Literacy in the lower primary schools. The question also sought to find out the extent to which the combined 90 minutes for both mother and English language is carried out and whether pupils learn better in a language they are familiar with or not.

Table 1: Teachers Opinions on Effective Involvement in the Implementation of NALAP and Language and Literacy $(\mathrm{N}-100)$

\begin{tabular}{|c|c|c|c|c|}
\hline $\begin{array}{l}\text { Implementation of NALAP and teaching of language and } \\
\text { literacy }\end{array}$ & Agree & Disagree & Total & $\begin{array}{l}\text { Percentage } \\
(\%)\end{array}$ \\
\hline $\begin{array}{l}\text { The School implemented combined language and literacy } \\
\text { policy of NALAP }\end{array}$ & $87(87 \%)$ & $\begin{array}{l}13 \\
(13 \%)\end{array}$ & 100 & 100 \\
\hline $\begin{array}{l}\text { The School implemented the combined } 90 \text { minutes literacy } \\
\text { period }\end{array}$ & $\begin{array}{l}74 \\
(74 \%)\end{array}$ & $\begin{array}{l}26 \\
(26 \%)\end{array}$ & 100 & 100 \\
\hline $\begin{array}{l}\text { Lower primary pupils learn to read and write in language } \\
\text { they speak and understand }\end{array}$ & $\begin{array}{l}88 \\
(88 \%)\end{array}$ & $\begin{array}{l}12 \\
(12 \%)\end{array}$ & 100 & 100 \\
\hline $\begin{array}{l}\text { Teachers are aware of } L 1 \text { and } L 2 \text { early grade literacy } \\
\text { programme }\end{array}$ & $\begin{array}{l}87 \\
(87 \%)\end{array}$ & $\begin{array}{l}13 \\
(13 \%)\end{array}$ & 100 & 100 \\
\hline $\begin{array}{l}\text { Teachers integrate other available literacy materials into } \\
\text { teaching language and literacy }\end{array}$ & $91(91 \%)$ & $9(9 \%)$ & 100 & 100 \\
\hline Total & & & 100 & 100 \\
\hline
\end{tabular}

Source: Field Data, 2017

Table 1 reveals that $87 \%$ of the respondent teachers admitted the school implemented the combined language and literacy policy of NALAP whilst $13 \%$ disagreed. In the same vein, $74 \%$ of the respondents agreed that the school implemented the 90 minutes literacy period policy and $26 \%$ also disagreed. This finding contradicts the NALAP Implementation Study report which indicated that $16 \%$ of all the classes observed were using the 90 minutes language and literacy period. This clearly showed that the policy was not totally implemented as the implementation study reports indicated in their findings that by June, 2010 only one-third of the schools had implemented the GES directive to change their timetables and introduce the new subject, Language and Literacy, as a 90 minute period combining L1 and English. It is believed that without the framework provided by the 90 minute Language and Literacy period, some teachers could not follow the guidance for the timing of activities in L1 and English provided in the Teacher Guide (EQUALL, 2010).

Again, $88 \%$ of the respondent teachers confirmed that lower primary pupils learn to read and write better in a language they can speak and understand. This finding also supports GES (2014) that mother-tongue (L1) based literacy instruction approach helps the child to develop literacy and language skill first in the L1 and systematically transfer these skills to the English language. Similarly, $87 \%$ of the respondents also affirmed that teachers were aware of the Ghanaian language and English early grade language and literacy policy and $13 \%$ disagreed. In the same way, $91 \%$ of respondents agreed that teachers integrate other available literacy materials into the teaching and learning of language and literacy in the lower primary schools whilst only $9 \%$ disagreed with the idea.

From Table 1, the findings is not conclusive that implementation is perfectly executed since some of the respondents disagreed. It is possible that some people did not think the implementation is actually effectively done. There seems to be dispute in the claim of implementation as one cannot clearly tell whether those who disagreed with the statements benefitted or are also part of the implementation. The reason of some disagreeing could be attributed to their lack of any form of training in the teaching of language and literacy.

Research Question 2: How efficiently have the teachers been using the teaching methodologies and strategies of NALAP in the teaching of language and literacy in the lower primary schools?

The rationale for this question was to assess the teachers' use of the teaching methodologies and strategies of the National Literacy Acceleration Programme to influence the performance of pupils at lower primary level in the language and literacy classes. The main focus of any literacy programme is how effective teachers use their pedagogical skills to improve pupils' literacy development and their skills. Table 2 illustrates the results of this research questions 
Table 2: Teachers' Views on the Use of NALAP Methods and Strategies in Language and Literacy Teaching (N-100)

\begin{tabular}{|c|c|c|c|c|}
\hline Teachers use of methods and strategies of NALAP & Agree & Disagree & Total & $\begin{array}{l}\text { Percentage } \\
(\%)\end{array}$ \\
\hline $\begin{array}{l}\text { Teachers use the lesson plan of NALAP in teaching } \\
\text { language and literacy }\end{array}$ & $\begin{array}{l}75 \\
(75 \%)\end{array}$ & $\begin{array}{l}25 \\
(25 \%)\end{array}$ & 100 & 100 \\
\hline $\begin{array}{l}\text { Teachers use the methods and strategies of NALAP in } \\
\text { teaching language and literacy }\end{array}$ & $\begin{array}{l}80 \\
(80 \%)\end{array}$ & $\begin{array}{l}20 \\
(20 \%)\end{array}$ & 100 & 100 \\
\hline Teachers use L1 and L2 in teaching language and literacy & $\begin{array}{l}97 \\
(97 \%)\end{array}$ & $3(3 \%)$ & 100 & 100 \\
\hline $\begin{array}{l}\text { Teachers follow the NALAP prescribed guide in their lesson } \\
\text { plans }\end{array}$ & $\begin{array}{l}71 \\
(71 \%)\end{array}$ & $\begin{array}{l}29 \\
(29 \%)\end{array}$ & 100 & 100 \\
\hline $\begin{array}{l}\text { Teachers are comfortable and proficient teaching language } \\
\text { and literacy }\end{array}$ & $\begin{array}{l}60 \\
(60 \%)\end{array}$ & $\begin{array}{l}40 \\
(40 \%)\end{array}$ & 100 & 100 \\
\hline Total & & & 100 & 100 \\
\hline
\end{tabular}

Source: Field Data, 2017

The results from Table 2 show that $75 \%$ of the respondents agreed that teachers use the lesson plan of NALAP in the lower primary schools while $25 \%$ disagreed. This view on the use of lesson plan is similar to that of Moomen (2006) study in the Bole district which revealed that $87.2 \%$ of the teachers prepared and used their lesson plans always. Also, $80 \%$ of the respondents admitted that teachers use the methodologies and strategies of NALAP in the teaching of language and literacy in the lower primary schools but $20 \%$ of the respondents did not agree. Again, 97\% of the respondents confirmed that teachers use the L1 and L2 in the teaching of language and literacy in the lower primary schools whilst only 3\% disagreed. This finding is in line with UNESCO (1953) affirmation that the use of L1 in education is psychologically, sociologically, and educationally beneficial to learners and that every effort should be made to provide education in the L1. To ensure freedom and human dignity for all Ghanaian children, the government of Ghana should ensure the use of the L1 policy is implemented to the letter.

This finding also supports Seidu (2011) study in 11 districts in Ghana which revealed that 55\% of teachers (426 out of 771) firmly supported the view that official permission should be granted for the use of both English and L1 in all subjects on the curriculum. Added to this, Seidu's (2011) finding also revealed that over 70\% (561 out of 776) teachers think the combined use of English Language and Ghanaian language is educationally beneficial to the pupils, that is $81 \%$ for lower primary and $64 \%$ for upper primary. Teachers therefore, preferred bilingual education to language specialization. The findings further indicated that teachers felt parents would be happy if primary school pupils are literates in both English and Ghanaian language by the end of year six primary programme. Above all, Seidu's (2011) findings concluded on the point of L1, that teachers supported the view that "language alternation" should be officially recognized as means of instruction at the lower primary levels.

With regards to the issue of whether teachers follow the NALAP prescribed Teacher Guide in the lesson planning, $71 \%$ of the respondents indicated they used it. As regard to whether teachers are comfortable and proficient in teaching of language and literacy, $60 \%$ affirmed to this whilst only $40 \%$ disagreed to this opinion.

The findings of this study has a strong support for the use of L1 instruction for the teaching and learning of language and literacy in the lower primary schools since there are a lot of research evidence in favour of the L1 instruction at lower primary levels. This is so because it is believed that when pupils learn language skills in L1 when gaining literacy skills in their familiar Ghanaian language, they establish a transferable set of skills that can make learning to read and write in English easier and quicker.

Research Question 3: To what extent has the use of NALAP materials been implemented in the lower primary schools?

This question sought to assess the extent to which the use of NALAP materials had been implemented in the teaching and learning of language and literacy in the lower primary. In addition, the question was also posed to find out whether the materials are even available, sufficient and put to good use in the lower primary schools. Added to this, the question again sought to find out about the current state of materials in the various lower primary schools. Table 3 captures the information on the use of NALAP materials. 
Table 3: Teachers Views on the Use of NALAP Materials in Teaching Language and Literacy (N-100)

$\begin{aligned} & \text { Use of NALAP materials in the teaching and learning of } \\ & \text { language and literacy }\end{aligned}$
$\begin{aligned} & \text { Teachers use the teacher guide and NALAP instructional } \\ & \text { materials in the planning and teaching of language and } \\ & \text { literacy }\end{aligned}$
Total

Source: Field Data, 2017

From Table 3, 72\% of the respondents indicated that they use the Teacher's Guide in planning and teaching of language and literacy, while $28 \%$ disagreed. In the same vein, $75 \%$ agreed that the Teacher's Guide is comprehensive enough for the teachers to use in teaching language and literacy while $25 \%$ also disagreed. This finding is in line with the NALAP implementation study findings which indicated that $99.4 \%$ of the teachers responded that the Teacher Guide was easy to use (EQUALL, 2010). With regard to the pupils' spoken language chosen for NALAP materials, 67\% of the respondent teachers affirmed that the spoken language is the same chosen for NALAP materials and is suitable to the local environment whilst $23 \%$ disagreed. This finding again also supports the NALAP implementation study which revealed $97.8 \%$ of the teachers said the materials were related to the child's environment and culture (EQUALL, 2010).

On the part of sufficient teaching and learning materials (TLM), 61\% disagreed that NALAP provided sufficient and adequate materials for both teachers and pupils in the teaching and learning of language and literacy. This finding is also related to Moomen's (2006) study which revealed that 25 teachers representing $64.1 \%$ felt the materials were insufficient. This clearly showed that teaching and learning materials were inadequately supplied to the schools for the National Literacy Acceleration Programme. The implication here is that most of the pupils in the language literacy classes did not benefit from effective use of teaching and learning materials and would not be able to acquire the intended needed skills in the L1and L2 as envisage by the NALAP.

However, the finding also contradicts part of the same Moomen (2006) study which said teachers enjoyed full complement and timely supply of teaching and learning materials in the BTL/BTE progrmme in the Bole District. Moomen (2006) finding contrary said it was not the same in the 'cycle 1' schools of BTL/BTE and that their materials arrived late and were not in the quantity as the pilot phase. This finding is almost similar to the implementation study of NALAP as it revealed that the materials distribution was not favourable to some schools just as the experience of Buoti primary school revealed in this study.

It should be noted that teaching and learning materials are an important part of every learning experience. According to T-TEL (2016), education research in Ghana and across sub-Saharan Africa provides evidence that teaching and learning materials are important part of a productive learning environment. The use of Teaching Learning Materials help pupils learn better in any topic. It further explained that while TLMs are an integral part of effective teaching and learning, they on their own do not lead to improve learning outcomes. The T-TEL went on to further explain that there was shortage of TLMs across schools and colleges.

With regards to availability of the materials, $63 \%$ agreed that materials were available while $37 \%$ disagreed that the materials were in the schools. This is also clear evidence that the materials were actually not available in all the schools since more than one-third of the respondents indicated that they were not available. The fact that NALAP materials were not sufficient or available in the schools could be attributed to lack of the materials in the system or some hidges in the distribution to the various schools in the districts.

In the research questionnaire, question 31 which was an open-ended one required respondents to suggest things they feel should be put in place for the effective teaching of language and literacy in the lower primary schools. Table 4 presents the results of the suggestions given by the respondents. 
Table 4: Teachers Suggested Means to Facilitate Effective Teaching of Language and Literacy (N-100)

Suggested means to facilitate effective teaching of language and literacy

Teaching and learning materials

Training and capacity building

Supervision and monitoring

Teacher motivation

Total

Source: Field Data, 2017

From Table 4, respondent teachers were required to make suggestions as to how to improve NALAP and language and literacy in the lower primary schools. It therefore, means one could give one, two or more suggestions. Though respondents were one hundred (100) for the questionnaire, hundred and thirty-five suggestions were received and coded into four themes as seen in Table 4

Out of the total of 135 suggestions, $70(52 \%)$ suggested that the provision of teaching and learning materials was necessary for language and literacy in the lower primary schools. Second on the suggestion, 46 (34\%) advocated for more training and capacity building for lower primary school teachers to enable them teach language and literacy effectively. The suggestions finding is similar to Moomen (2006) study on the issues of the way forward where respondents unanimously advocated for more refresher courses and training of teachers in BTL/BTE project. In addition, 12 (9\%) of the respondent teachers in this study suggested that supervision and monitoring should be intensified. However, a few respondent teachers suggested teachers' motivation as a tool for proper implementation and progress of NALAP. It is evident that teachers were not much concern about their personal motivation but felt their professional development is paramount if language and literacy teaching is to be successful. This is seen in the way the teachers made their suggestions.

Interview was conducted on ten teachers and Table 5 shows the results of the views of the respondents

Table 5: Interview Results of Respondent Teachers on NALAP (N-10)

\begin{tabular}{llll}
\hline Item & Yes & No & Total \\
\hline Teachers have training in NALAP and Literacy Teaching & $90 \%$ & $10 \%$ & $100 \%$ \\
The Mother Tongue is important in teaching language and Literacy & $100 \%$ & $00 \%$ & $100 \%$ \\
Teacher can read Ghanaian Language fluently (Dagaare or Sisaali) & $70 \%$ & $30 \%$ & $100 \%$ \\
NALAP Materials are Available in School & $70 \%$ & $30 \%$ & $100 \%$ \\
Teachers use Teacher Guide for teaching language and literacy & $50 \%$ & $50 \%$ & $100 \%$ \\
Teachers have difficulty in the use of materials for teaching Language & $60 \%$ & $40 \%$ & $100 \%$ \\
and Literacy & & $100 \%$ \\
NALAP Materials are related to the environment and culture of the & $80 \%$ & $20 \%$ & $100 \%$ \\
pupils & & $50 \%$ & $100 \%$ \\
Teachers have training again on NALAP or Language and Literacy & $50 \%$ & & $100 \%$ \\
teaching & $90 \%$ & $30 \%$ & $10 \%$ \\
Teachers face Difficulties in the teaching of language and Literacy & $90 \%$ & $100 \%$ \\
NALAP, Language and Literacy policy is necessary & &
\end{tabular}

\section{Source: Field Data, 2017}

Table 5 shows that all the $10(100 \%)$ teachers interviewed admitted that the use of the mother tongue was important in the teaching and learning of language and literacy in the lower primary schools. In support of the claim on the use of mother tongue, 9 (90\%) of the respondent teachers also indicated that the language and literacy policy was necessary in the lower primary school. This revelation falls in line with Wilmot \& Wilmot (2013) assertion that there is evidence that children do not learn better when second language either than the mother tongue is used for instruction.

In the same vein $9(90 \%)$ of the respondents admitted that they had training in language and literacy and contrary indicated that they had difficulty teaching language and literacy. Again, $8(80 \%)$ of the respondents indicated that NALAP materials were related to the environment and culture of the pupils. This is affirmation on whether NALAP materials were related to the environment and culture of the pupils goes to confirm what Dolphyne, (1998) said that language mirrors people's culture and it is a matter of obligation to develop and sustain our languages. Also $6(60 \%)$ of the respondents affirmed that they had difficulty using the materials. This finding is in consonance with Moomen (2006) study of the Break Through to Literacy (BTL) in Bole district which revealed $69.2 \%$ of teachers said they had difficulty using the teaching and learning materials. On the part of using the Teacher Guide, $5(50 \%)$ respondent teachers confirmed that they use it. This goes to confirm the NALAP Implementation Study report which revealed that 170 (88\%) were using the Teacher Guide in the classrooms. This clearly shows how uncertain whether the teachers were really using the Teachers' Guide, if the respondents are just half $(50 \%)$ of them who agreed they were using it. It is not certain whether teachers are really dedicated to the use of NALAP Teacher Guide. In respect of the ability to read and write in the mother 
tongue, $70 \%$ of the respondent teachers said they could read the mother tongue and the same number answered that NALAP materials were available in the lower primary schools.

From the results in Table 5, it clearly shows that there is lack of commitment on the part of the respondent teachers if $90 \%$ said they had training and at the same time revealed that they had difficulty teaching language and literacy or using the materials. The result is controversial because if the respondent teachers had training, it is assumed they had knowledge in the area and should therefore be able to handle it using the materials provided. From this revelation, it is possible teachers after going for training were not practicing what they learned and did not receive any further training after their initial training.

In addition, during the interview in the two Sissala districts, teachers expressed their concern that the L1 approved (Dagaare) was not the children's L1 and as such, most teachers felt it was not necessary to teach it since it is also an L2 to the pupils. They suggested that the books and all NALAP materials should have been written in Sissali. Some even concluded that the approved language was imposed on them because at the Junior High School (JHS) level candidates of the Basic Education Certificate Examination (BECE) are compelled to write Dagaare which is not their MT/L1 against their wish. This revelation is an indication that it is possible teachers from the two districts disagreed to some of the statements on the materials and L1 used in the classroom.

One of the instruments used in this study was document analysis to find out the state of the materials. Table 6 presents the results on the document analysis.

Table 6: Results of Document Analysis Collected from the Various Schools (N-20)

\begin{tabular}{|c|c|c|c|c|c|}
\hline & Present & Absent & \multicolumn{2}{|c|}{ Percentage } & Total \\
\hline Teacher Guide for KG 1-P3 & 20 & 0 & $100 \%$ & $00 \%$ & 20 \\
\hline Textbooks & 11 & 9 & $55 \%$ & $45 \%$ & 20 \\
\hline Big Books & 16 & 4 & $80 \%$ & $20 \%$ & 20 \\
\hline Conversational Poster for KG1-P1 & 15 & 5 & $75 \%$ & $25 \%$ & 20 \\
\hline Phone Cards & 10 & 10 & $50 \%$ & $50 \%$ & 20 \\
\hline Supplementary Readers for p2 \& 3 & 13 & 7 & $65 \%$ & $35 \%$ & 20 \\
\hline Lesson Notes & 20 & 00 & $100 \%$ & $00 \%$ & 20 \\
\hline Pupils Exercises & 14 & 6 & $70 \%$ & $30 \%$ & 20 \\
\hline Let's Read and Write & 15 & 5 & $75 \%$ & $25 \%$ & 20 \\
\hline Pupils Books for P2, $2 \& 3$ & 9 & 11 & $45 \%$ & $55 \%$ & 20 \\
\hline Alphabet Cards & 9 & 11 & $45 \%$ & $55 \%$ & 20 \\
\hline Word Cards & 7 & 13 & $35 \%$ & $65 \%$ & 20 \\
\hline Letter Cards & 8 & 12 & $40 \%$ & $60 \%$ & 20 \\
\hline Supplementary Readers & 16 & 4 & $80 \%$ & $20 \%$ & 20 \\
\hline Pupils Books & 10 & 10 & $50 \%$ & $50 \%$ & 20 \\
\hline
\end{tabular}

Source: Field Data, 2017

The data in Table 6 shows that some of the schools do not have some of the teaching and learning materials designed and supplied to schools on the National Literacy Acceleration Programme. The only document found in all the schools was the Teacher Guide with $100 \%$ supply to the schools. This finding is similar to the results of Rapid Assessment Survey cited in EQUALL (2010) where there was no prior notice given to the districts and schools of the visit where it revealed that $75 \%$ of the schools received and were using the Teacher Guide. Similarly, EQUALL survey, carried out throughout also indicated $90 \%$ of the schools and teachers were using the Teacher Guide in the KG-P3.

On the issue of lesson notes, it is clear almost all the $20(100 \%)$ teachers indicated they have been preparing lesson notes but from observation, some did not follow the NALAP procedures as planned in the Teacher Guides. This finding is consonance with Moomen (2006) study of the 'Break Through Literacy' (BTL) in Bole District which revealed $87.2 \%$ of the respondents indicated that they prepared lesson notes. Other documents such as the Big Books (80\%), Conversational Posters (75\%), Let's Read and Write (75\%), Text Book (55\%), Supplementary Readers $(65 \%)$ and other Readers $(80 \%)$ were also available in some of the lower primary schools. Exercises for the pupils were also found to be carried out in some schools but they were inadequate.

Despite the fact that these documents were available in some schools, they were not put into good use as others. They were found in the offices of the teachers during the document analysis session. However, some schools such as $31^{\text {st }}$ December KG, St Gabriel and Egala in the Sissala East put theirs' into good use. Similarly, St Andrews in Wa, Eremon Tangzu in Lawra, St Joseph in Jirapa districts respectively also had theirs' put into good use. Sissala West was the one with the least NALAP materials supplied to the schools. For instance, Buoti Primary school in particular had only one Teacher Guide and none of the rest of the materials except the lesson notes of teachers and pupils' exercises.

The teachers in Buoti school of Sissala West felt this research study was their source of help because the school is old without early childhood development centre and lacks facilities and teaching learning materials. Luckily, the Circuit Supervisor who was also there with me collecting information on behalf of the Member of 
Parliament (MP) disclosed to the teachers that the MP has promised to assist the school with most of their needs.

\subsection{Results and Discussion \\ Research Question 1}

How effective is the involvement of teachers in the implementation of the NALAP in the teaching of Language and Literacy?

This question sought to find out how effectively teachers are involved in the implementation of the National Literacy Acceleration Programme in the teaching and learning of Language and Literacy in the lower primary schools. The question also sought to find out the extent to which the combined 90 minutes for both mother and English language is carried out and whether pupils learn better in a language they are familiar with or not.

Table 1: Teachers Opinions on Effective Involvement in the Implementation of NALAP and Language and Literacy (N-100)

\begin{tabular}{|c|c|c|c|c|}
\hline $\begin{array}{l}\text { Implementation of NALAP and teaching of language and } \\
\text { literacy }\end{array}$ & Agree & Disagree & Total & $\begin{array}{l}\text { Percentage } \\
(\%)\end{array}$ \\
\hline $\begin{array}{l}\text { The School implemented combined language and literacy } \\
\text { policy of NALAP }\end{array}$ & $87(87 \%)$ & $\begin{array}{l}13 \\
(13 \%)\end{array}$ & 100 & 100 \\
\hline $\begin{array}{l}\text { The School implemented the combined } 90 \text { minutes literacy } \\
\text { period }\end{array}$ & $\begin{array}{l}74 \\
(74 \%)\end{array}$ & $\begin{array}{l}26 \\
(26 \%)\end{array}$ & 100 & 100 \\
\hline $\begin{array}{l}\text { Lower primary pupils learn to read and write in language } \\
\text { they speak and understand }\end{array}$ & $\begin{array}{l}88 \\
(88 \%)\end{array}$ & $\begin{array}{l}12 \\
(12 \%)\end{array}$ & 100 & 100 \\
\hline $\begin{array}{l}\text { Teachers are aware of } L 1 \text { and } L 2 \text { early grade literacy } \\
\text { programme }\end{array}$ & $\begin{array}{l}87 \\
(87 \%)\end{array}$ & $\begin{array}{l}13 \\
(13 \%)\end{array}$ & 100 & 100 \\
\hline $\begin{array}{l}\text { Teachers integrate other available literacy materials into } \\
\text { teaching language and literacy }\end{array}$ & $91(91 \%)$ & $9(9 \%)$ & 100 & 100 \\
\hline Total & & & 100 & 100 \\
\hline
\end{tabular}

Table 1 reveals that $87 \%$ of the respondent teachers admitted the school implemented the combined language and literacy policy of NALAP whilst $13 \%$ disagreed. In the same vein, $74 \%$ of the respondents agreed that the school implemented the 90 minutes literacy period policy and $26 \%$ also disagreed. This finding contradicts the NALAP Implementation Study report which indicated that $16 \%$ of all the classes observed were using the 90 minutes language and literacy period. This clearly showed that the policy was not totally implemented as the implementation study reports indicated in their findings that by June, 2010 only one-third of the schools had implemented the GES directive to change their timetables and introduce the new subject, Language and Literacy, as a 90 minute period combining L1 and English. It is believed that without the framework provided by the 90 minute Language and Literacy period, some teachers could not follow the guidance for the timing of activities in L1 and English provided in the Teacher Guide (EQUALL, 2010).

Again, $88 \%$ of the respondent teachers confirmed that lower primary pupils learn to read and write better in a language they can speak and understand. This finding also supports GES (2014) that mother-tongue (L1) based literacy instruction approach helps the child to develop literacy and language skill first in the L1 and systematically transfer these skills to the English language. Similarly, $87 \%$ of the respondents also affirmed that teachers were aware of the Ghanaian language and English early grade language and literacy policy and $13 \%$ disagreed. In the same way, $91 \%$ of respondents agreed that teachers integrate other available literacy materials into the teaching and learning of language and literacy in the lower primary schools whilst only $9 \%$ disagreed with the idea.

From Table 1, the findings is not conclusive that implementation is perfectly executed since some of the respondents disagreed. It is possible that some people did not think the implementation is actually effectively done. There seems to be dispute in the claim of implementation as one cannot clearly tell whether those who disagreed with the statements benefitted or are also part of the implementation. The reason of some disagreeing could be attributed to their lack of any form of training in the teaching of language and literacy.

Research Question 2: How efficiently have the teachers been using the teaching methodologies and strategies of NALAP in the teaching of language and literacy in the lower primary schools?

The rationale for this question was to assess the teachers' use of the teaching methodologies and strategies of the National Literacy Acceleration Programme to influence the performance of pupils at lower primary level in the language and literacy classes. The main focus of any literacy programme is how effective teachers use their pedagogical skills to improve pupils' literacy development and their skills. Table 2 illustrates the results of this research questions 
Table 2: Teachers' Views on the Use of NALAP Methods and Strategies in Language and Literacy Teaching (N-100)

\begin{tabular}{|c|c|c|c|c|}
\hline Teachers use of methods and strategies of NALAP & Agree & Disagree & Total & $\begin{array}{l}\text { Percentage } \\
(\%)\end{array}$ \\
\hline $\begin{array}{l}\text { Teachers use the lesson plan of NALAP in teaching } \\
\text { language and literacy }\end{array}$ & $\begin{array}{l}75 \\
(75 \%)\end{array}$ & $\begin{array}{l}25 \\
(25 \%)\end{array}$ & 100 & 100 \\
\hline $\begin{array}{l}\text { Teachers use the methods and strategies of NALAP in } \\
\text { teaching language and literacy }\end{array}$ & $\begin{array}{l}80 \\
(80 \%)\end{array}$ & $\begin{array}{l}20 \\
(20 \%)\end{array}$ & 100 & 100 \\
\hline Teachers use $\mathrm{L} 1$ and $\mathrm{L} 2$ in teaching language and literacy & $\begin{array}{l}97 \\
(97 \%)\end{array}$ & $3(3 \%)$ & 100 & 100 \\
\hline $\begin{array}{l}\text { Teachers follow the NALAP prescribed guide in their lesson } \\
\text { plans }\end{array}$ & $\begin{array}{l}71 \\
(71 \%)\end{array}$ & $\begin{array}{l}29 \\
(29 \%)\end{array}$ & 100 & 100 \\
\hline $\begin{array}{l}\text { Teachers are comfortable and proficient teaching language } \\
\text { and literacy }\end{array}$ & $\begin{array}{l}60 \\
(60 \%)\end{array}$ & $\begin{array}{l}40 \\
(40 \%)\end{array}$ & 100 & 100 \\
\hline Total & & & 100 & 100 \\
\hline
\end{tabular}

Source: Field Data, 2017

The results from Table 2 show that $75 \%$ of the respondents agreed that teachers use the lesson plan of NALAP in the lower primary schools while $25 \%$ disagreed. This view on the use of lesson plan is similar to that of Moomen (2006) study in the Bole district which revealed that $87.2 \%$ of the teachers prepared and used their lesson plans always. Also, $80 \%$ of the respondents admitted that teachers use the methodologies and strategies of NALAP in the teaching of language and literacy in the lower primary schools but $20 \%$ of the respondents did not agree. Again, 97\% of the respondents confirmed that teachers use the L1 and L2 in the teaching of language and literacy in the lower primary schools whilst only 3\% disagreed. This finding is in line with UNESCO (1953) affirmation that the use of L1 in education is psychologically, sociologically, and educationally beneficial to learners and that every effort should be made to provide education in the L1. To ensure freedom and human dignity for all Ghanaian children, the government of Ghana should ensure the use of the L1 policy is implemented to the letter.

This finding also supports Seidu (2011) study in 11 districts in Ghana which revealed that 55\% of teachers (426 out of 771) firmly supported the view that official permission should be granted for the use of both English and L1 in all subjects on the curriculum. Added to this, Seidu's (2011) finding also revealed that over $70 \%$ (561out of 776) teachers think the combined use of English Language and Ghanaian language is educationally beneficial to the pupils, that is $81 \%$ for lower primary and $64 \%$ for upper primary. Teachers therefore, preferred bilingual education to language specialization. The findings further indicated that teachers felt parents would be happy if primary school pupils are literates in both English and Ghanaian language by the end of year six primary programme. Above all, Seidu's (2011) findings concluded on the point of L1, that teachers supported the view that "language alternation" should be officially recognized as means of instruction at the lower primary levels.

With regards to the issue of whether teachers follow the NALAP prescribed Teacher Guide in the lesson planning, $71 \%$ of the respondents indicated they used it. As regard to whether teachers are comfortable and proficient in teaching of language and literacy, $60 \%$ affirmed to this whilst only $40 \%$ disagreed to this opinion.

The findings of this study has a strong support for the use of L1 instruction for the teaching and learning of language and literacy in the lower primary schools since there are a lot of research evidence in favour of the L1 instruction at lower primary levels. This is so because it is believed that when pupils learn language skills in L1 when gaining literacy skills in their familiar Ghanaian language, they establish a transferable set of skills that can make learning to read and write in English easier and quicker.

Research Question 3: To what extent has the use of NALAP materials been implemented in the lower primary schools?

This question sought to assess the extent to which the use of NALAP materials had been implemented in the teaching and learning of language and literacy in the lower primary. In addition, the question was also posed to find out whether the materials are even available, sufficient and put to good use in the lower primary schools. Added to this, the question again sought to find out about the current state of materials in the various lower primary schools. Table 3 captures the information on the use of NALAP materials. 
Table 3: Teachers Views on the Use of NALAP Materials in Teaching Language and Literacy (N-100) language and literacy

\begin{tabular}{|c|c|c|c|c|}
\hline Teachers use the teacher guide and NALAP & $72(72 \%)$ & $28(28 \%)$ & 100 & 100 \\
\hline \multicolumn{5}{|l|}{$\begin{array}{l}\text { instructional materials in the planning and teaching of } \\
\text { language and literacy }\end{array}$} \\
\hline $\begin{array}{l}\text { NALAP teacher guide is comprehensive enough for use } \\
\text { in teaching language and literacy }\end{array}$ & $75(75 \%)$ & $25(25 \%)$ & 100 & 100 \\
\hline $\begin{array}{l}\text { Pupils' spoken language is same chosen for the NALAP } \\
\text { materials and is suitable to local environment }\end{array}$ & $67(67 \%)$ & $33(33 \%)$ & 100 & 100 \\
\hline \multicolumn{2}{|c|}{ NALAP provided sufficient and adequate mm materials materia19 (39\%) } & $61(61 \%)$ & 100 & 100 \\
\hline NALAP materials are used in other lessons & $68(68 \%)$ & $32(32 \%)$ & 100 & 100 \\
\hline NALAP materials are available in the school & $63(63 \%)$ & $37(37 \%)$ & 100 & 100 \\
\hline Total & & & 100 & 100 \\
\hline
\end{tabular}
Total

Source: Field Data, 2017

From Table 3, 72\% of the respondents indicated that they use the Teacher's Guide in planning and teaching of language and literacy, while $28 \%$ disagreed. In the same vein, $75 \%$ agreed that the Teacher's Guide is comprehensive enough for the teachers to use in teaching language and literacy while $25 \%$ also disagreed. This finding is in line with the NALAP implementation study findings which indicated that $99.4 \%$ of the teachers responded that the Teacher Guide was easy to use (EQUALL, 2010). With regard to the pupils' spoken language chosen for NALAP materials, $67 \%$ of the respondent teachers affirmed that the spoken language is the same chosen for NALAP materials and is suitable to the local environment whilst $23 \%$ disagreed. This finding again also supports the NALAP implementation study which revealed $97.8 \%$ of the teachers said the materials were related to the child's environment and culture (EQUALL, 2010).

On the part of sufficient teaching and learning materials (TLM), 61\% disagreed that NALAP provided sufficient and adequate materials for both teachers and pupils in the teaching and learning of language and literacy. This finding is also related to Moomen's (2006) study which revealed that 25 teachers representing $64.1 \%$ felt the materials were insufficient. This clearly showed that teaching and learning materials were inadequately supplied to the schools for the National Literacy Acceleration Programme. The implication here is that most of the pupils in the language literacy classes did not benefit from effective use of teaching and learning materials and would not be able to acquire the intended needed skills in the L1and L2 as envisage by the NALAP.

However, the finding also contradicts part of the same Moomen (2006) study which said teachers enjoyed full complement and timely supply of teaching and learning materials in the BTL/BTE progrmme in the Bole District. Moomen (2006) finding contrary said it was not the same in the 'cycle 1' schools of BTL/BTE and that their materials arrived late and were not in the quantity as the pilot phase. This finding is almost similar to the implementation study of NALAP as it revealed that the materials distribution was not favourable to some schools just as the experience of Buoti primary school revealed in this study.

It should be noted that teaching and learning materials are an important part of every learning experience. According to T-TEL (2016), education research in Ghana and across sub-Saharan Africa provides evidence that teaching and learning materials are important part of a productive learning environment. The use of Teaching Learning Materials help pupils learn better in any topic. It further explained that while TLMs are an integral part of effective teaching and learning, they on their own do not lead to improve learning outcomes. The T-TEL went on to further explain that there was shortage of TLMs across schools and colleges.

With regards to availability of the materials, $63 \%$ agreed that materials were available while $37 \%$ disagreed that the materials were in the schools. This is also clear evidence that the materials were actually not available in all the schools since more than one-third of the respondents indicated that they were not available. The fact that NALAP materials were not sufficient or available in the schools could be attributed to lack of the materials in the system or some hidges in the distribution to the various schools in the districts.

In the research questionnaire, question 31 which was an open-ended one required respondents to suggest things they feel should be put in place for the effective teaching of language and literacy in the lower primary schools. Table 4 presents the results of the suggestions given by the respondents. 
Table 4: Teachers Suggested Means to Facilitate Effective Teaching of Language and Literacy (N-100) Suggested means to facilitate effective teaching of Frequency (no. of suggestions) Percentage language and literacy

\begin{tabular}{lll}
\hline Teaching and learning materials & 70 & $52 \%$ \\
Training and capacity building & 46 & $34 \%$ \\
Supervision and monitoring & 12 & $9 \%$ \\
Teacher motivation & 7 & $5 \%$ \\
\hline Total & $\mathbf{1 3 5}$ & $\mathbf{1 0 0 \%}$ \\
\hline
\end{tabular}

Source: Field Data, 2017

From Table 4, respondent teachers were required to make suggestions as to how to improve NALAP and language and literacy in the lower primary schools. It therefore, means one could give one, two or more suggestions. Though respondents were one hundred (100) for the questionnaire, hundred and thirty-five suggestions were received and coded into four themes as seen in Table 4

Out of the total of 135 suggestions, $70(52 \%)$ suggested that the provision of teaching and learning materials was necessary for language and literacy in the lower primary schools. Second on the suggestion, 46 (34\%) advocated for more training and capacity building for lower primary school teachers to enable them teach language and literacy effectively. The suggestions finding is similar to Moomen (2006) study on the issues of the way forward where respondents unanimously advocated for more refresher courses and training of teachers in BTL/BTE project. In addition, $12(9 \%)$ of the respondent teachers in this study suggested that supervision and monitoring should be intensified. However, a few respondent teachers suggested teachers' motivation as a tool for proper implementation and progress of NALAP. It is evident that teachers were not much concern about their personal motivation but felt their professional development is paramount if language and literacy teaching is to be successful. This is seen in the way the teachers made their suggestions.

Interview was conducted on ten teachers and Table 5 shows the results of the views of the respondents

Table 5: Interview Results of Respondent Teachers on NALAP (N-10)

\begin{tabular}{|c|c|c|c|}
\hline Item & Yes & No & Total \\
\hline Teachers have training in NALAP and Literacy Teaching & $90 \%$ & $10 \%$ & $100 \%$ \\
\hline $\begin{array}{l}\text { The Mother Tongue is important in teaching language and } \\
\text { Literacy }\end{array}$ & $100 \%$ & $00 \%$ & $100 \%$ \\
\hline $\begin{array}{l}\text { Teacher can read Ghanaian Language fluently (Dagaare or } \\
\text { Sisaali) }\end{array}$ & $70 \%$ & $30 \%$ & $100 \%$ \\
\hline NALAP Materials are Available in School & $70 \%$ & $30 \%$ & $100 \%$ \\
\hline Teachers use Teacher Guide for teaching language and literacy & $50 \%$ & $50 \%$ & $100 \%$ \\
\hline $\begin{array}{l}\text { Teachers have difficulty in the use of materials for teaching } \\
\text { Language and Literacy }\end{array}$ & $60 \%$ & $40 \%$ & $100 \%$ \\
\hline $\begin{array}{l}\text { NALAP Materials are related to the environment and culture of } \\
\text { the pupils }\end{array}$ & $80 \%$ & $20 \%$ & $100 \%$ \\
\hline $\begin{array}{l}\text { Teachers have training again on NALAP or Language and } \\
\text { Literacy teaching }\end{array}$ & $50 \%$ & $50 \%$ & $100 \%$ \\
\hline Teachers face Difficulties in the teaching of language and Literacy & $90 \%$ & $30 \%$ & $100 \%$ \\
\hline NALAP, Language and Literacy policy is necessary & $90 \%$ & $10 \%$ & $100 \%$ \\
\hline
\end{tabular}

Source: Field Data, 2017

Table 5 shows that all the $10(100 \%)$ teachers interviewed admitted that the use of the mother tongue was important in the teaching and learning of language and literacy in the lower primary schools. In support of the claim on the use of mother tongue, $9(90 \%)$ of the respondent teachers also indicated that the language and literacy policy was necessary in the lower primary school. This revelation falls in line with Wilmot \& Wilmot (2013) assertion that there is evidence that children do not learn better when second language either than the mother tongue is used for instruction.

In the same vein $9(90 \%)$ of the respondents admitted that they had training in language and literacy and contrary indicated that they had difficulty teaching language and literacy. Again, $8(80 \%)$ of the respondents indicated that NALAP materials were related to the environment and culture of the pupils. This is affirmation on whether NALAP materials were related to the environment and culture of the pupils goes to confirm what Dolphyne, (1998) said that language mirrors people's culture and it is a matter of obligation to develop and sustain our languages. Also $6(60 \%)$ of the respondents affirmed that they had difficulty using the materials. This finding is in consonance with Moomen (2006) study of the Break Through to Literacy (BTL) in Bole district which revealed $69.2 \%$ of teachers said they had difficulty using the teaching and learning materials. On the part of using the Teacher Guide, $5(50 \%)$ respondent teachers confirmed that they use it. This goes to confirm the NALAP Implementation Study report which revealed that $170(88 \%)$ were using the Teacher Guide in the classrooms. This clearly shows how uncertain whether the teachers were really using the Teachers' Guide, if the 
respondents are just half $(50 \%)$ of them who agreed they were using it. It is not certain whether teachers are really dedicated to the use of NALAP Teacher Guide. In respect of the ability to read and write in the mother tongue, $70 \%$ of the respondent teachers said they could read the mother tongue and the same number answered that NALAP materials were available in the lower primary schools.

From the results in Table 5, it clearly shows that there is lack of commitment on the part of the respondent teachers if $90 \%$ said they had training and at the same time revealed that they had difficulty teaching language and literacy or using the materials. The result is controversial because if the respondent teachers had training, it is assumed they had knowledge in the area and should therefore be able to handle it using the materials provided. From this revelation, it is possible teachers after going for training were not practicing what they learned and did not receive any further training after their initial training.

In addition, during the interview in the two Sissala districts, teachers expressed their concern that the L1 approved (Dagaare) was not the children's L1 and as such, most teachers felt it was not necessary to teach it since it is also an L2 to the pupils. They suggested that the books and all NALAP materials should have been written in Sissali. Some even concluded that the approved language was imposed on them because at the Junior High School (JHS) level candidates of the Basic Education Certificate Examination (BECE) are compelled to write Dagaare which is not their MT/L1 against their wish. This revelation is an indication that it is possible teachers from the two districts disagreed to some of the statements on the materials and L1 used in the classroom.

One of the instruments used in this study was document analysis to find out the state of the materials. Table 6 presents the results on the document analysis.

Table 6: Results of Document Analysis Collected from the Various Schools (N-20)

\begin{tabular}{|c|c|c|c|c|c|}
\hline & Present & Absent & Perce & & Total \\
\hline Teacher Guide for KG 1-P3 & 20 & 0 & $100 \%$ & $00 \%$ & 20 \\
\hline Textbooks & 11 & 9 & $55 \%$ & $45 \%$ & 20 \\
\hline Big Books & 16 & 4 & $80 \%$ & $20 \%$ & 20 \\
\hline Conversational Poster for KG1-P1 & 15 & 5 & $75 \%$ & $25 \%$ & 20 \\
\hline Phone Cards & 10 & 10 & $50 \%$ & $50 \%$ & 20 \\
\hline Supplementary Readers for p2 \& 3 & 13 & 7 & $65 \%$ & $35 \%$ & 20 \\
\hline Lesson Notes & 20 & 00 & $100 \%$ & $00 \%$ & 20 \\
\hline Pupils Exercises & 14 & 6 & $70 \%$ & $30 \%$ & 20 \\
\hline Let's Read and Write & 15 & 5 & $75 \%$ & $25 \%$ & 20 \\
\hline Pupils Books for P2, $2 \& 3$ & 9 & 11 & $45 \%$ & $55 \%$ & 20 \\
\hline Alphabet Cards & 9 & 11 & $45 \%$ & $55 \%$ & 20 \\
\hline Word Cards & 7 & 13 & $35 \%$ & $65 \%$ & 20 \\
\hline Letter Cards & 8 & 12 & $40 \%$ & $60 \%$ & 20 \\
\hline Supplementary Readers & 16 & 4 & $80 \%$ & $20 \%$ & 20 \\
\hline Pupils Books & 10 & 10 & $50 \%$ & $50 \%$ & 20 \\
\hline
\end{tabular}

Source: Field Data, 2017

The data in Table 6 shows that some of the schools do not have some of the teaching and learning materials designed and supplied to schools on the National Literacy Acceleration Programme. The only document found in all the schools was the Teacher Guide with $100 \%$ supply to the schools. This finding is similar to the results of Rapid Assessment Survey cited in EQUALL (2010) where there was no prior notice given to the districts and schools of the visit where it revealed that $75 \%$ of the schools received and were using the Teacher Guide. Similarly, EQUALL survey, carried out throughout also indicated $90 \%$ of the schools and teachers were using the Teacher Guide in the KG-P3.

On the issue of lesson notes, it is clear almost all the $20(100 \%)$ teachers indicated they have been preparing lesson notes but from observation, some did not follow the NALAP procedures as planned in the Teacher Guides. This finding is consonance with Moomen (2006) study of the 'Break Through Literacy' (BTL) in Bole District which revealed $87.2 \%$ of the respondents indicated that they prepared lesson notes. Other documents such as the Big Books (80\%), Conversational Posters (75\%), Let's Read and Write (75\%), Text Book (55\%), Supplementary Readers $(65 \%)$ and other Readers $(80 \%)$ were also available in some of the lower primary schools. Exercises for the pupils were also found to be carried out in some schools but they were inadequate.

Despite the fact that these documents were available in some schools, they were not put into good use as others. They were found in the offices of the teachers during the document analysis session. However, some schools such as $31^{\text {st }}$ December KG, St Gabriel and Egala in the Sissala East put theirs' into good use. Similarly, St Andrews in Wa, Eremon Tangzu in Lawra, St Joseph in Jirapa districts respectively also had theirs' put into good use. Sissala West was the one with the least NALAP materials supplied to the schools. For instance, Buoti Primary school in particular had only one Teacher Guide and none of the rest of the materials except the lesson notes of teachers and pupils' exercises.

The teachers in Buoti school of Sissala West felt this research study was their source of help because the 
school is old without early childhood development centre and lacks facilities and teaching learning materials. Luckily, the Circuit Supervisor who was also there with me collecting information on behalf of the Member of Parliament (MP) disclosed to the teachers that the MP has promised to assist the school with most of their needs.

\subsection{Conclusions}

The study sought to examine the use of NALAP methods, strategies and materials in the teaching of language and literacy in the lower primary schools after the implementation. The goal was to understand whether the teachers at the lower primary levels have implemented NALAP instruction strategies and whether they use the materials in their classrooms, especially in teaching language and literacy. It was not the researcher's intent to assess and judge the schools based on the data collected, but to use the data to help inform professional development and increase support for teaching and learning of language and literacy in the lower classes.

Therefore, from the results discussed in this study, it can be concluded and recommended that; teachers need to be trained to be competent in the use of the L1 and L2 instruction and communication to enable them handle the teaching and learning of language and literacy at the lower primary levels. Colleges of Education also need to properly incorporate bi-literacy instructional methodology into their training programmes so that after completion, trainees will be able to implement the skills acquired in teaching language and literacy. In addition to that, in-service training as well as adequate teaching and learning materials and other resources should be provided by the government to already practicing teachers, pre-service teachers and newly recruited teachers to ensure efficient and effective progress of already existing early childhood literacy programmes.

\subsection{Suggestion for Further Study}

The study could have covered a wider area, but due to financial constraints and other challenges, it was limited in scope as far as the sample coverage was concerned. It is hoped this study could be replicated and carried out on a large scale in all the schools in the Upper West Region of Ghana to assess the extent to which the National Literacy Acceleration as well as the language and literacy is implemented in lower primary schools.

\section{REFERENCES}

Andoh-Kumi, K. (1992). An Investigation into the Relationship between Bilingualism and School Achievement.An unpublished Ph.D. thesis. University of Ghana: Institute of African Studies.

Dolphyne, F. A. (1998). Effective Communication in Nation Building: The Place of Ghanaian Languages. A Paper Presented at NAFAC, Bolgatanga.

Dowuona-Hammond, C. \& Asante-Frempong, R. (2000).Implementation of the School English Only Language Policy of Education. In Selected Proceedings of the 35th Annual Review of Applied Linguistics 7: 133-146.

Duut, G. N. \& Nanglakong, C. D. (2019). Socio-Cultural Traits and Connection among the Ethnic Clans of Bimoba, Konkomba, Sissala and Dagaaba in the Northern Part of Ghana. The International Journal of Humanities and Social Studies. Vol. 7 no. 2, p. 154-165

EQUALL, (2010). National Literacy Acceleration Program (NALAP) Implementation Study. Accra, Ghana: USAID.

Fafunwa, A. B., Macauley, J. I., and Funnso, S. (1989). Education in Mother Tongue. The Ife: University of Ibadan

Ghana Education Service (2014). Inset Source Book for the Teaching of Language and Literacy: Lower Primary. Accra: MOE.

Ghana Education Service (2014). Inset Source Book/Manual for the Teaching of Language and Literacy: English Manual for Junior High School. Accra: MOE.

Leherr, K. (2009). National Literacy Acceleration Program (NALAP) Baseline Assessment. Accra: EDC for USAID.

Ministry of Education (2014). Ghana 2013 Early Grade Reading Assessment and Early Grade Mathematics Assessment: Reports of Findings. Accra: GES. 60pp.

Ministry of Education (2015). Learning: Why Reading Matters. Accra: GES.

Ministry of Education Science and Sports (2008). Let's Read and Write. Primary 1, Teacher's. Guide.Northern Version. Ghana: Ghana Education Service.

Ministry of Education, Science and Sports (2007). Teaching syllabuses for English language. Monitoring Report .ESOL Quarterly 8: 129-136.

Ministry of Education/ Ghana Education Service (2014). Ghana 2013 National Education Assessment, Summary of Results. Ghana: USAID.

Moomen, A. S. (2006). Evaluation Survey of the 'Break Through to Literacy' and 'Bridge to English' Project in Bole District.Unpublished Masters' Dissertation. UEW, Winneba.

National Educational Assessment (2012). Ghana National Educational Assessment. 2011 Report. Accra: Ghana 
Education Service.

Ouedraogu, M. R. (2000). Language Planning and Language Policyin Selected West Africsn Countries. Burkina Faso: University of Burkina Faso.

Owu-Ewie, C. (2013). The National Acceleration Program and the Language Policy Education in Ghana. International Journal of Basic Education, 1(3),95-104.

Owu-Ewie, C.( 2006).The Language Policy of Education in Ghana: A Critical Look at the English language Education. In selected Proceedings of African Linguistics. J. Mugane et al 76-85, Somerville, Cascdille Proceedings Project.

Print, M. (1993). Curriculum Development and Design. ( $2^{\text {nd }}$ ed.). NSW, Australia: Allen \&Unwin Pt.

Seidu, A. (2011). Implementation of the Language Policy at the Pre-University level in Ghana: International Journal of Pedagogy, Policy and ICT in Education. Vol.1 no. 2, p. 37-52.

Seidu, A., Mereku, D. K., Avoke, M., Ekumah, E. M. J. \&Adzahlie-Mensah, V. (2008). 'Report on Teacher Capacity for Local Language instruction' Accra: Equall/NALAP Task Force (USAID Sponsored)

Tamanja, E. M. J. (2010). Attitude of Teacher on the Medium of Instruction Policy in Basic Schools in Savelugu-Nanton District and Tamale Metropolis; Implication for Education. International Journal of Pedagogy, Polic and ICT in Education, 1(2), 79-90.

Transforming Teacher Education and Learning (T-TEL) (2016). Professional Development Programme: National Teachers' Standards and Teacher Education Curriculum Framework for Ghana. Ghana: Government of Ghana, Ukaid.

UNESCO (1953).The Use of Vernacular Languages in Education.Report of the UNESCO. Paris: UNESCO. 